Research Article

\title{
Safety Threshold Determination for Blasting Vibration of the Lining in Existing Tunnels under Adjacent Tunnel Blasting
}

\author{
Fei Xue $\mathbb{D}^{1},{ }^{1,2,3}$ Caichu Xia $\mathbb{D}^{2,3,4}$ Guoliang Li, ${ }^{2}$ Baocheng Jin, ${ }^{2}$ Yongwang He, ${ }^{2}$ \\ and Yapeng $\mathrm{Fu}^{2}$ \\ ${ }^{1}$ Collaborative Innovation Center for Prevention and Control of Mountain Geological Hazards of Zhejiang Province, \\ College of Civil Engineering, Shaoxing University, Shaoxing, Zhejiang 312000, China \\ ${ }^{2}$ Shaanxi Railway and Underground Traffic Engineering Key Laboratory (FSDI), Xi'an, Shaanxi 710000, China \\ ${ }^{3}$ Key Laboratory of Rock Mechanics and Geohazards of Zhejiang Province, Shaoxing University, Shaoxing, \\ Zhejiang 312000, China \\ ${ }^{4}$ Key Laboratory of Geotechnical and Underground Engineering, Ministry of Education of China, Tongji University, \\ Shanghai 200092, China
}

Correspondence should be addressed to Caichu Xia; tjxiaccb@126.com

Received 23 April 2019; Revised 27 July 2019; Accepted 19 August 2019; Published 19 September 2019

Academic Editor: Tayfun Dede

Copyright (C) 2019 Fei Xue et al. This is an open access article distributed under the Creative Commons Attribution License, which permits unrestricted use, distribution, and reproduction in any medium, provided the original work is properly cited.

\begin{abstract}
The effects of tunnel blast excavation on the lining structures of adjacent tunnels are comprehensively studied for the Xinling highway tunnel project. First, the LS-DYNA software is applied to obtain the characteristics of vibration velocities and dynamic stresses at different positions of the tunnel liner. The results indicate that the maximum peak particle velocity (PPV) is located on the haunch of the lining facing the blasting source and that the PPV and peak tensile stress decrease with the increase in the surrounding rock grade. Second, a site test on blasting vibration is conducted to verify the simulation results. By using regression analysis of the measured vibration data, the calculation method of maximum charge per delay for optimizing blasting excavation under different surrounding rock grades is obtained. Finally, based on the statistical relationship between crack alteration and PPV on the lining before and after blasting, the safety thresholds of PPV for different portions of the tunnel are determined. The recommended safety threshold of PPV is $10 \mathrm{~cm} / \mathrm{s}$ for intact lining and for B-grade and V-grade linings of the surrounding rock tunnel. However, if the lining crack grade falls between $1 \mathrm{~A}$ and $\mathrm{B}$, then the recommended safety thresholds of PPV for the IIIgrade and IV-grade surrounding rock tunnel are $5 \mathrm{~cm} / \mathrm{s}$ and $6 \mathrm{~cm} / \mathrm{s}$, respectively. The threshold PPV proposed in this study has been successfully applied to restrict blast-induced damage during new tunnel excavation of the Xinling tunnel project.
\end{abstract}

\section{Introduction}

In recent years, with the rapid development of China's transportation system, a large number of single-track tunnels have been expanded to double track tunnels [1]. To save land resources, to reduce construction costs and to protect the environment, the distance between the old tunnel and the new tunnel must be as short as possible. However, vibrations induced by adjacent tunnels when they are excavated by the drill and blast method could jeopardize the safety of existing service tunnels. Blasting vibrations induced by tunnel excavation or nearby mining might cause spalling, fissures, cracks, or even collapse of existing tunnel linings [2].
The PPV is widely used as a safety criterion for existing tunnels in China and other countries. Due to the complexity of underground structure response under blasting vibration, there are no uniform provisions on the safety threshold of blasting vibration velocity $[3,4]$. Lin et al. [5] investigated the safety threshold of the blasting vibration velocity used in practical engineering and revealed that the safety thresholds of different projects are quite different, ranging from 1.8 to $25 \mathrm{~cm} / \mathrm{s}$. Bauer and Calder [6], according to the relationship between rock damage and particle vibration velocity, noted that the extent of damage to the rock is not only related to the peak velocity but also to the mechanical properties of the surrounding rock. Xia et al. [7] used a field test and a 
numerical simulation method to study the relationship between the PPV of the existing tunnel and the extent of damage to the surrounding rock in the Damaoshan highway tunnel project, and the PPV criteria for different parts of the tunnel were determined based on the relationship. It is therefore necessary to conduct both experimental and numerical research to propose a reasonable threshold of blasting vibration velocity to ensure the safety of the lining of the existing tunnel.

Many researchers have studied the dynamic response of blast vibrations, such as the variations of velocity, acceleration, frequency, wave propagation, damage, and stress induced by blasting. For example, Sun et al. [8] studied the influence of step blast-excavation in newly built tunnels on the support structures of the existing service tunnel through field experimentation and numerical simulation to obtain the blasting vibration velocity, frequency, and the range and degree of damage of the support structures. Liang et al. [9] investigated the impacts of blast-induced vibrations from the construction of a new tunnel on an existing railway tunnel and the effect of both the static stress before blasting vibrations and the dynamic stress induced by blasting on the total stresses in the existing tunnel lining. Xu et al. [10] carried out field tests and numerical simulation to study the relationships between the blasting vibration velocity and the frequency over time, horizontal distance, and depth, and the stress distribution of the surrounding rock mass. Duan et al. [11] and Huo et al. [12] investigated the vibration velocity and vibration frequency of the existing structure and proposed a guideline for the blast safety zone based on vibration velocity, main frequency, and explosive quantity. Duan et al. [13] studied the stress distribution of the surrounding rock and the propagation mode of the stress wave during blasting.

However, little research has been carried out to study the relationship between the initial health of the tunnels and the degree of dynamic response to blasting vibration. Due to the differences in the service times of existing tunnels, the geological conditions of the surrounding rock and the stress state of the lining structure, the degree of dynamic response to blasting disturbance varies. In the present paper, in support of underground blasting excavation for the Xinling highway tunnels in Zhuji, Zhejiang Province, South China, a dynamic finite element program, LS-DYNA, was used to calculate the PPV and dynamic stress distribution characteristic of the existing tunnel lining under different geological conditions. The results of the simulation were compared with those of field tests to verify the numerical model, and the safety threshold of the PPV for the existing tunnel lining was put forward based on a systematic analysis of the relationship between crack alteration and the PPV on the lining before and after blasting.

\section{Brief Description of the Project}

The Xinling highway tunnel project is composed of two existing tunnels in between two new tunnels. It is a straight and parallel tunnel group that is $1400 \mathrm{~m}$ in length. The new tunnels have dimensions of $17.58 \mathrm{~m} \times 7.2 \mathrm{~m}$ (span $\times$ height), and the existing tunnels have dimensions of $10.75 \mathrm{~m} \times 5 \mathrm{~m}$. The spacing between the two existing tunnels and the two new ones is $27.29 \mathrm{~m}$ and $23.08 \mathrm{~m}$, respectively, as shown in Figure 1. The rock around the tunnels is mainly composed of carbonaceous shale, argillaceous limestone and weathered siltstone, which have obvious joints and fractures. Overall, the rock ratings for the two existing tunnels are $850 \mathrm{~m}$ or $60.7 \%$ for grade III, $283 \mathrm{~m}$ or $20.2 \%$ for grade IV and $267 \mathrm{~m}$ or $19.1 \%$ for grade V. The rock masses were classified based on the Chinese Code for the Design of Road Tunnels (JTG D70-2004) [14], which considers many influence factors, such as the strength of intact rock, the geometrical characteristics and mechanical properties of discontinuity, the intactness of the rock mass, groundwater, and ground stress.

According to the surrounding rock grade of the Xinling tunnel, different excavation construction schemes were selected on the working face to control the quantity of blasting explosives and reduce the impact of blasting on the existing tunnels; these schemes include the advanced large pipe-shed or small catheter + ring-excavation with the center soil reserved or two-sidewall pilot construction method for grade $\mathrm{V}$, the advance small catheter + positive step excavation method for grade IV, and the advance bolt + full-face excavation method for grade III. To ensure the safe operation of existing tunnels and the secure construction of new tunnels, it is necessary to monitor the vibration velocity of the existing tunnel lining during the excavation of new tunnels. To avoid blasting vibration superposition, millisecond-controlled blasting was adopted in the excavation. According to the Chinese "Safety Regulation for Blasting" [15], which is listed in Table 1, the safety threshold for PPV of existing tunnels was assumed to be $10 \mathrm{~cm} / \mathrm{s}$. The arrangement of the blastholes and the grooves for grade III surrounding rock is presented in Figure 2. The indirect initiation was adopted with low-speed explosives and a nonelectric millisecond detonator. The delay time of the millisecond delay detonator is $50 \mathrm{~ms}$. Wedge cutting and smooth blasting with a noncoupled air column charge structure were utilized with a hole diameter of $42 \mathrm{~mm}$ and a drug diameter of $32 \mathrm{~mm}$. The single-cycle footage for grade III surrounding rock was $3 \mathrm{~m}$ with 18 cutting holes and a 2.4-kg charge weight per hole. Due to the largest single-stage charge weight of the cutting holes, the vibration intensity induced by the blasting is great; thus, the research mainly focuses on the blasting excavation induced by vibration of the cutting holes.

\section{Numerical Simulation and Analysis}

3.1. Numerical Model. To fully understand the dynamic response on existing tunnel lining structures under blastexcavation load, the plane strain dynamic FEM method is used to analyze surrounding rock of grade III (YK47 + 725), grade IV (YK47 + 790), and grade (VZK46+700). The calculated parameters of each section are shown in Table 2. Previous publications have indicated that the strongest vibrations of the existing tunnel lining are proportional to the maximum segmental explosive charge instead of the total charge [2]. Therefore, only cutting blasting was simulated to simplify the model and reduce the amount of calculation.

To reduce the influence of the boundary effect, the left, right, and lower boundaries of the FEM model were taken 


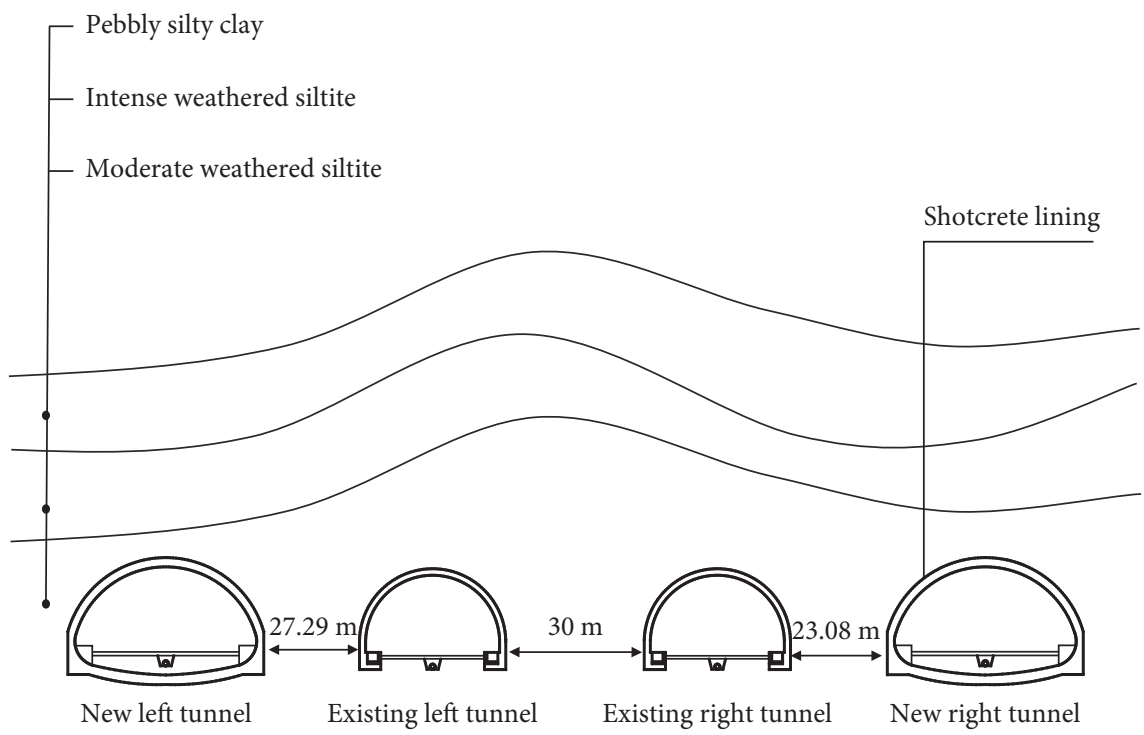

FIgURE 1: Sectional view of tunnel configuration and geological information.

TABLe 1: Safety vibration limitation for tunnels and shafts in China.

\begin{tabular}{lccc}
\hline Structure type & & Allowable safety peak particle velocity $(\mathrm{cm} / \mathrm{s})$ \\
& $f \leq 10 \mathrm{~Hz}$ & $10 \mathrm{~Hz} \leq f \leq 50 \mathrm{~Hz}$ & $f 3.0$ \\
Hydraulic tunnels & $7 \sim 8$ & 37.0 & 3 \\
Traffic tunnels & $10 \sim 12$ & 31.5 & 2 \\
Mining shafts & $15 \sim 18$ & 1.5 \\
\hline
\end{tabular}

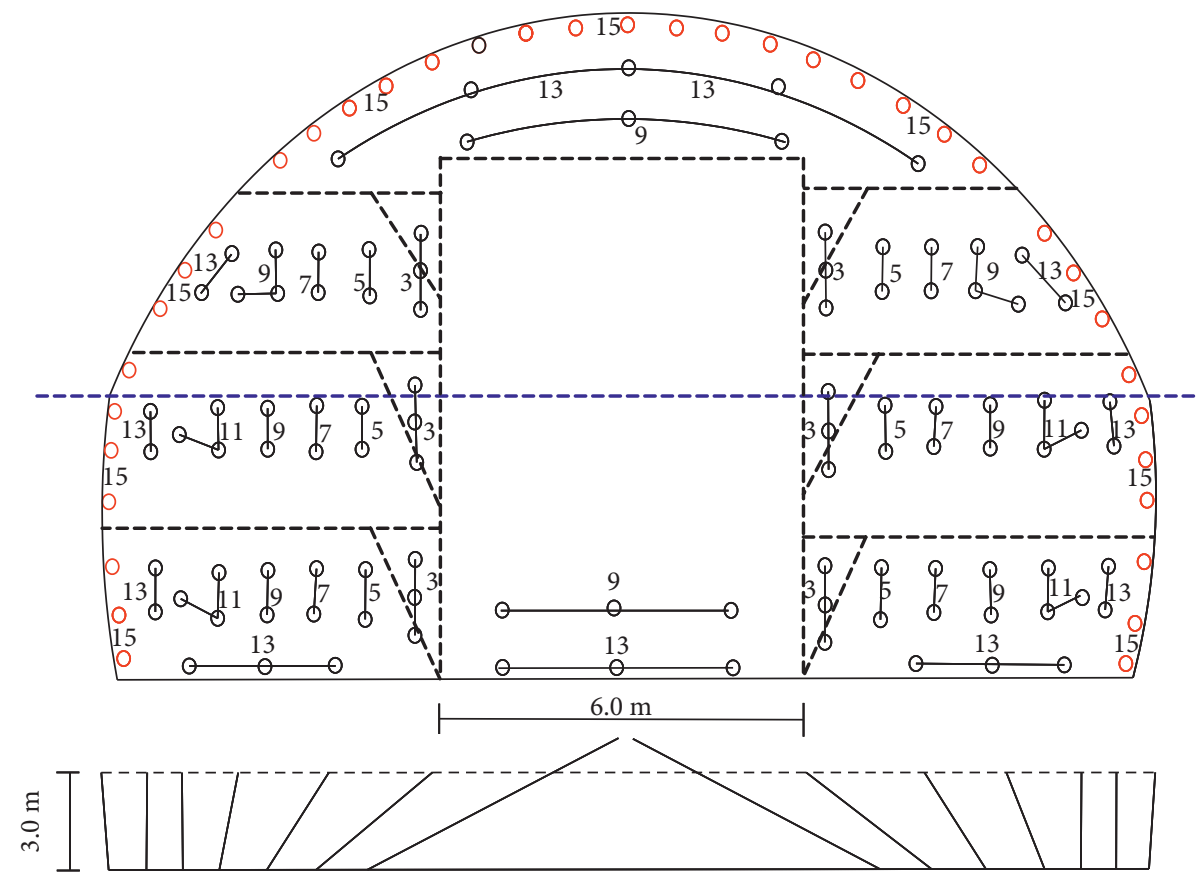

FIGURE 2: Layout of the blasthole and groove for grade III surrounding rock.

as three times the width of the tunnel, the $X$ and $Y$ directions are $85 \mathrm{~m}$ and $50 \mathrm{~m}$, respectively, and the $Z$ direction is the corresponding blasting footage. To facilitate the division of the grid, only new tunnel cutting holes were modeled. To prevent the deformity of the grid, the numerical model of the cutting holes is parallel to the tunneling direction, and the centers of the two are the same. The radii of the explosive and air models are $1.6 \mathrm{~cm}$ and $2.1 \mathrm{~cm}$, respectively. The numerical simulation is shown in Figure 3. 
TABLe 2: The calculated parameters of each typical section.

\begin{tabular}{lccccc}
\hline Rock mass & Position & Distance from explosive source $(\mathrm{m})$ & Blasting footage $(\mathrm{m})$ & Cut holes number & Cutting holes charge $(\mathrm{kg})$ \\
\hline Grade III & YK47 +725 & 39.0 & 3 & 18 & 43.2 \\
Grade IV & YK47 +790 & 37.0 & 2 & 12 & 24 \\
Grade V & ZK46+700 & 31.5 & 1.5 & 6 & 21 \\
\hline
\end{tabular}

3.2. Material Model and Parameters. The parameters of the MAT_PLASTIC_KINEMATIC model with different parameters for the surrounding rock and the lining are shown in Table 3. In the model, high-performance explosive materials within LS-DYNA were used to simulate the explosion process of emulsion explosive, which was defined by the keyword MAT_HIGH_EXPLOSIVE_BURN and the JonesWilkins-Lee (JWL) state equation [16]. The material parameters of the explosive are shown in Table 4 . The state equation is as follows:

$$
P_{\text {eos }}=A\left(1-\frac{\omega}{R_{1} V}\right) e^{-R_{1} V}+B\left(1-\frac{\omega}{R_{2} V}\right) e^{-R_{2} V}+\frac{\omega E_{0}}{V}
$$

where $P_{\text {eos }}$ is the detonation pressure, $V$ is the relative volume, $E_{0}$ is the initial energy per initial volume, and $A, B$, $R_{1}, R_{2}$, and $\omega$ are parameters related to charging the explosive.

3.3. Calculation Results. The PPV distributions of the key points on the existing tunnel linings are shown in Table 5 and Figure 4. From Table 5 and Figure 4, it can be seen that the PPV facing the blasting source is larger than the PPV in the blasting backside due to the near detonating source position. The PPV facing the blasting source is approximately 1.49-1.68 times the PPV in the blasting backside. The PPV in the blasting backside is generally small, and the maximum value is only $6.36 \mathrm{~cm} / \mathrm{s}$. Therefore, the tunnel lining in the blasting backside is relatively safe. The maximum PPV of the tunnel lining under different conditions is located on the haunch of the lining facing the blasting source, which is the most dangerous position; thus, it should be the key monitoring object for subsequent vibration monitoring.

Because of the propagation characteristics of the wave, the vibration velocity in the vertical direction of the tunnel lining surface is significantly higher than that in the horizontal direction, and the velocity in the vertical direction is 1.06-4.75 times the horizontal velocity. Therefore, the vertical velocity plays a major role in the control of the blasting vibration. In addition, the maximum PPV of the existing tunnel lining is $10.7 \mathrm{~cm} / \mathrm{s}$, which is slightly greater than the preset safety threshold for PPV of $10 \mathrm{~cm} / \mathrm{s}$, and the PPV of both existing tunnels decreases with the increase in the surrounding rock grade. The maximum PPV of the tunnel is only $2.01 \mathrm{~cm} / \mathrm{s}$ under grade $\mathrm{V}$ surrounding rock, which is only $1 / 5$ of the PPV of the tunnel under grade III surrounding rock. Because of the influence of the joints and cracks in the surrounding rock, the attenuation rate of blasting vibration in the loose broken rock is significantly greater than that in the intact surrounding rock.
The distributions of peak stress on the key points of the existing tunnel lining under different surrounding rock grades are shown in Table 6. From Table 6, it can be concluded that the dynamic disturbance caused by blasting excavation on the existing tunnel lining was mainly dynamic tensile stress, and the peak tensile stress on the lining decreases with the decrease in the PPV.

The peak tensile stress under different surrounding rock grades does not vary significantly. The maximum peak tensile stress is $0.67 \mathrm{MPa}$, which reaches $61 \%$ of the standard value of the tensile strength of the concrete lining, and the dynamic safety factor of the lining is 1.6. To ensure the safety of the existing tunnels during blasting excavation of the new tunnels, the peak tensile stress due to blasting should have a certain safety reserve value. Therefore, it is feasible to set $10 \mathrm{~cm} / \mathrm{s}$ as the safety threshold for the PPV of the existing tunnel lining.

Furthermore, there is no significant difference in the peak stress of blasting between the face side and the backside, and the peak stress in the position of the arch feet is greater than that of the rest. Therefore, it can be concluded that, under the current blasting charge and blasting mode, the influence of blasting excavation on the stability of the existing tunnel lining structure is limited, which can meet the requirements of construction safety. The numerical simulation results show that the blasting scheme of existing tunnels is feasible and can be implemented according to this blasting scheme.

\section{Field Vibration Monitoring and Analysis}

4.1. Monitoring Scheme. To verify the correctness of the numerical simulation results and understand the attenuation law of blasting vibration, PPV monitoring of the existing tunnel lining was conducted during the construction of new tunnels. Figure 5 illustrates the schematic arrangement of the measurement points. Four vibration monitoring points were set in a range of approximately $20 \mathrm{~m}$ before and after the location of the new tunnel excavating face. According to the above numerical simulation results, the maximum vibration velocity of blasting vibration is located on the haunch of the blasting facing-side, and the main vibration is vertical. Thus, the blasting vibration monitoring of this project mainly focuses on the vertical vibration velocity of the existing tunnel lining. The TC-4850 blasting vibration measurer was adopted to record the velocity-time histories of a vibration monitoring target, which is produced by Chengdu Zhongke Measurement \& Control Co., Ltd.

4.2. Analysis of the Monitoring Results. The PPV distribution interval statistics of the tunnel under different surrounding rock grades is shown in Figure 6. Figure 6 reveals that the PPV of the existing tunnel lining is mainly concentrated 


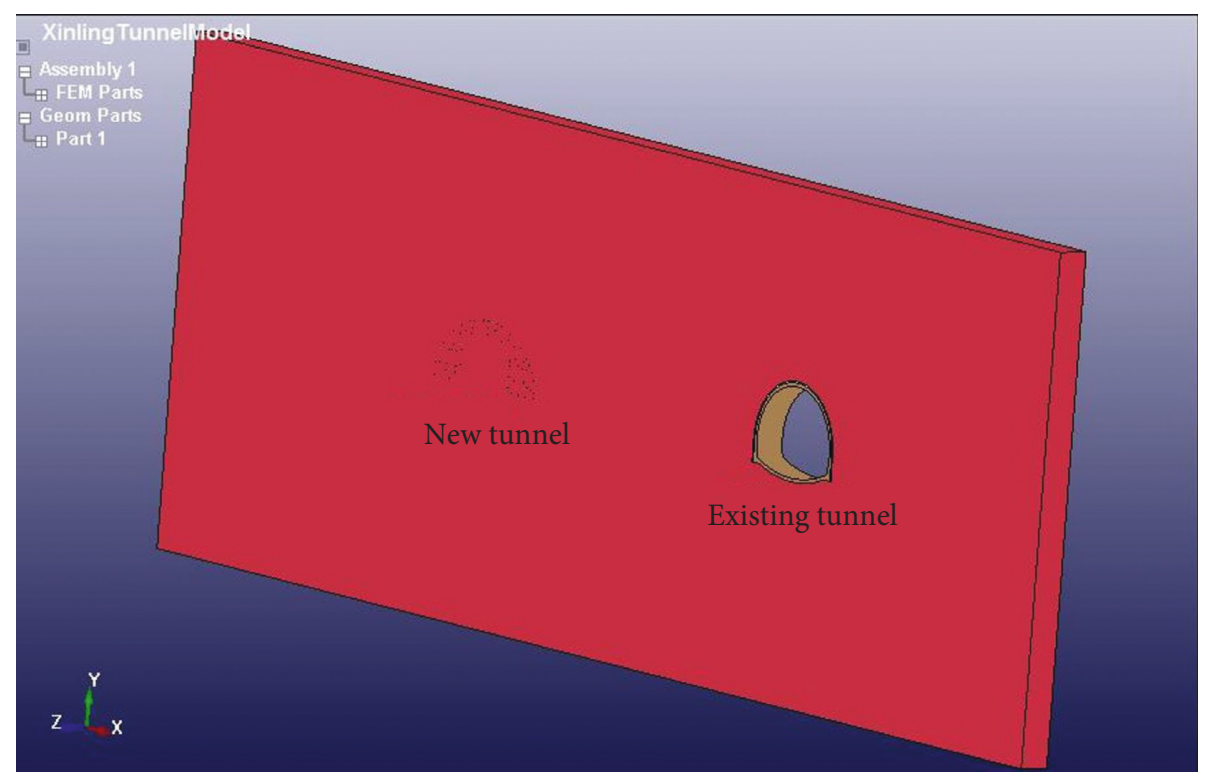

Figure 3: Calculation model of blasting excavation.

TABle 3: Physical and mechanical parameters of the rock and the lining.

\begin{tabular}{|c|c|c|c|c|c|}
\hline Material & Density $\left(\mathrm{g} / \mathrm{cm}^{-3}\right)$ & $E(\mathrm{GPa})$ & $\mu$ & $\sigma_{\mathrm{c}}(\mathrm{MPa})$ & $K(\mathrm{GPa})$ \\
\hline III-grade rock mass & 2.73 & 41.3 & 0.25 & 66.9 & 16.5 \\
\hline IV-grade rock mass & 2.70 & 38.6 & 0.25 & 64.6 & 15.6 \\
\hline V-grade rock mass & 2.67 & 35.2 & 0.25 & 50.8 & 14.7 \\
\hline Shotcrete & 2.36 & 25.5 & 0.20 & 13.4 & 10.6 \\
\hline Secondary lining & 2.40 & 28.0 & 0.20 & 16.7 & 11.7 \\
\hline
\end{tabular}

TABLE 4: Explosive parameters.

\begin{tabular}{lcccccccc}
\hline Density $\left(\mathrm{g} / \mathrm{cm}^{-3}\right)$ & Detonation velocity $(\mathrm{m} / \mathrm{s})$ & Detonation pressure $(\mathrm{GPa})$ & $A(\mathrm{GPa})$ & $B(\mathrm{GPa})$ & $R_{1}$ & $R_{2}$ & $\omega(\mathrm{GPa})$ & $E_{0}(\mathrm{GPa})$ \\
\hline 1.0 & 4500 & 506 & $5.24 e 4$ & 76.9 & 4.2 & 1.0 & 0.3 & 0.85 \\
\hline
\end{tabular}

TABLe 5: The PPV of the existing tunnel lining.

\begin{tabular}{|c|c|c|c|c|c|c|c|c|c|c|}
\hline \multirow{3}{*}{ Simulated condition } & \multirow{3}{*}{ Vibration direction } & \multicolumn{9}{|c|}{ PPV of key point $(\mathrm{cm} / \mathrm{s})$} \\
\hline & & \multirow{2}{*}{ Arch crown } & \multicolumn{4}{|c|}{ Blasting facing side } & \multicolumn{4}{|c|}{ Blasting backside } \\
\hline & & & Arch feet & Sidewall & Haunch & Spandrel & Arch feet & Sidewall & Haunch & Spandrel \\
\hline \multirow{2}{*}{ III-grade rock mass } & $X$-direction & 5.99 & 6.23 & 8.86 & 10.70 & 8.38 & 5.26 & 5.33 & 5.46 & 6.36 \\
\hline & $Y$-direction & 4.63 & 4.45 & 3.95 & 2.25 & 3.66 & 3.96 & 2.64 & 1.66 & 4.13 \\
\hline \multirow{2}{*}{ IV-grade rock mass } & $X$-direction & 1.22 & 1.53 & 2.43 & 2.66 & 1.82 & 1.43 & 1.67 & 1.72 & 1.63 \\
\hline & $Y$-direction & 1.15 & 0.90 & 0.59 & 0.64 & 1.24 & 0.90 & 0.63 & 0.82 & 1.34 \\
\hline \multirow{2}{*}{ V-grade rock mass } & $X$-direction & 0.98 & 1.01 & 1.87 & 2.01 & 1.31 & 0.97 & 1.22 & 1.35 & 1.01 \\
\hline & $Y$-direction & 0.68 & 0.69 & 0.56 & 0.51 & 0.90 & 0.60 & 0.47 & 0.69 & 0.88 \\
\hline
\end{tabular}

within $5 \mathrm{~cm} / \mathrm{s}$, which accounts for $93.11 \%$ of all field monitoring data. Only 14 PPVs exceed $10 \mathrm{~cm} / \mathrm{s}$, and all of them are concentrated in the tunnel portions of grade III surrounding rock. Therefore, it is appropriate to use $10 \mathrm{~cm} / \mathrm{s}$ as the safety threshold of PPV in the Xinling tunnel.

The monitoring data of the blasting vibration at typical sections selected in the numerical simulation are shown in Table 7. It can be seen from Table 7 that the PPV of field monitoring is consistent with that of numerical simulation, and the error is approximately 5\%. The PPV obtained by numerical simulation is slightly larger than the PPV of on- site monitoring. This finding shows that it is feasible and reliable to analyze and predict the influence of the blasting excavation of new tunnels on the lining structure of the existing tunnels through numerical calculation.

During the blasting construction of new tunnels, the monitoring group conducted a series of vibration tests and accumulated monitoring data for the existing tunnels under different blasting excavation methods and different surrounding rock conditions. As the blasting vibration is related to many factors, such as excavation scheme, maximum singlestage charge, rock strength and distance from blasting source 


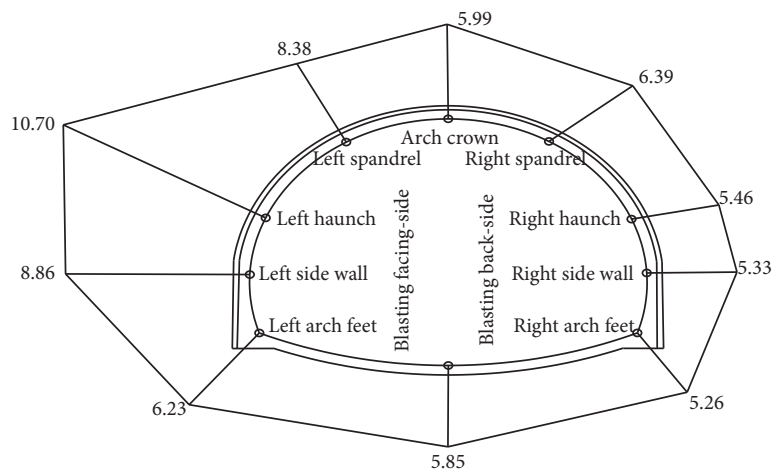

(a)

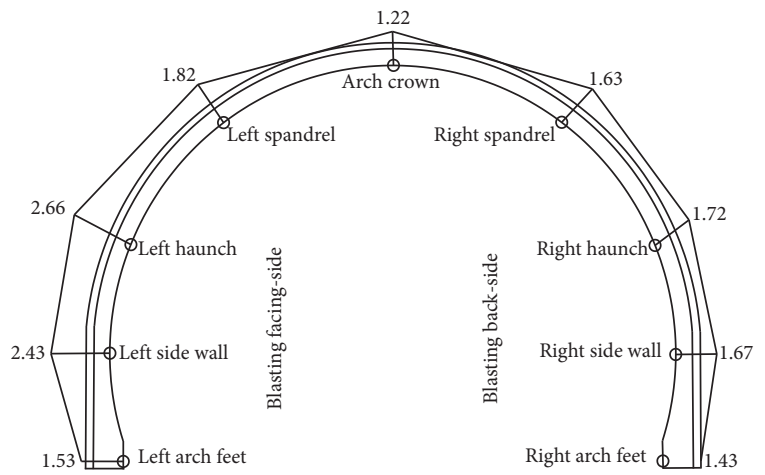

(b)

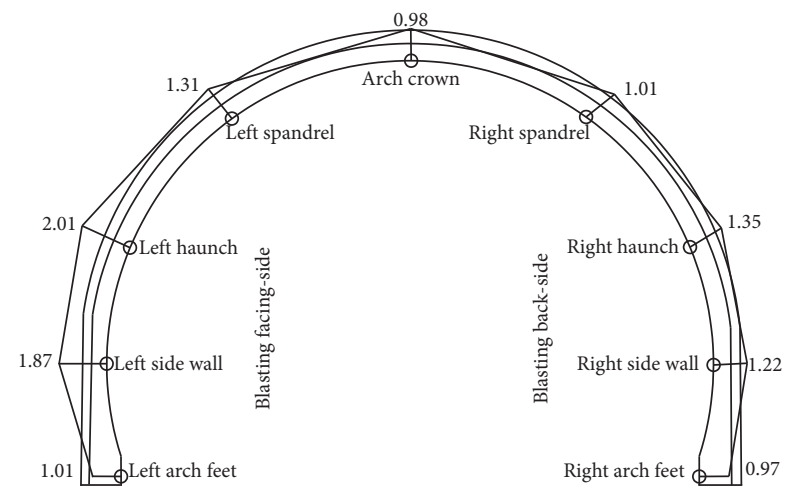

(c)

FIGURE 4: The PPV distribution of the existing tunnel lining under different surrounding rock grades. (a) Grade III rock mass. (b) Grade IV rock mass. (c) Grade V rock mass.

TABle 6: The peak stress of key point on the existing tunnel lining.

\begin{tabular}{|c|c|c|c|c|c|c|c|c|c|c|}
\hline \multirow{3}{*}{ Simulated condition } & \multirow{3}{*}{ Stress } & \multicolumn{9}{|c|}{ Peak stress of key point (MPa) } \\
\hline & & \multirow{2}{*}{ Arch crown } & \multicolumn{4}{|c|}{ Blasting facing-side } & \multicolumn{4}{|c|}{ Blasting backside } \\
\hline & & & Arch feet & Sidewall & Haunch & Spandrel & Arch feet & Sidewall & Haunch & Spandrel \\
\hline \multirow{2}{*}{ III-grade rock mass } & Tensile stress & 0.57 & 0.67 & 0.38 & 0.44 & 0.48 & 0.56 & 0.37 & 0.40 & 0.43 \\
\hline & Compressive stress & 0.53 & 0.54 & 0.40 & 0.42 & 0.39 & 0.56 & 0.46 & 0.48 & 0.51 \\
\hline \multirow{2}{*}{ IV-grade rock mass } & Tensile stress & 0.36 & 0.36 & 0.17 & 0.20 & 0.26 & 0.43 & 0.17 & 0.19 & 0.32 \\
\hline & Compressive stress & 0.31 & 0.23 & 0.18 & 0.20 & 0.23 & 0.41 & 0.19 & 0.27 & 0.25 \\
\hline \multirow{2}{*}{$\mathrm{V}$-grade rock mass } & Tensile stress & 0.29 & 0.32 & 0.14 & 0.21 & 0.31 & 0.26 & 0.14 & 0.24 & 0.24 \\
\hline & Compressive stress & 0.33 & 0.35 & 0.18 & 0.17 & 0.29 & 0.29 & 0.15 & 0.24 & 0.24 \\
\hline
\end{tabular}

Control standards

$1.10 \mathrm{MPa}$ (compression strength design value for $\mathrm{C} 20$ concrete); $9.60 \mathrm{MPa}$ (tensile strength design value for $\mathrm{C} 20$ concrete)

[10-12], even if under the same surrounding rock grade, the attenuation rate of PPV will vary because of the different degrees of blasting disturbance. If Sadov's empirical formula is used to regress the PPV of the surrounding rock conditions, then the correlation coefficient of regression will be low, and the regression results cannot ensure that the PPV will be controlled within a reasonable range. Therefore, we should first find the slowest attenuation monitoring data under the different surrounding rock grades and then proceed to the regression analysis. The fitting equations obtained by regression analysis of the slowest attenuation date would be reasonable for calculating the maximum single-stage charge in the subsequent construction to control the PPV.
To determine the variations in the attenuation rates of the PPV under the same surrounding rock grade, the equivalent PPV of each group of monitoring data can be obtained by equivalent transformation based on Sadov's formula, and we can sort the site monitoring data according to the magnitude of the equivalent PPV.

$$
V=K\left(\frac{\sqrt[3]{\mathrm{Q}}}{R}\right)^{\alpha} .
$$

Here, $V$ is the PPV, $Q$ is the maximum single-stage charge, $R$ is the distance from the blasting source, and $K$ and $\alpha$ are site-specific coefficients related to the blasting conditions and geotechnical characteristics. 


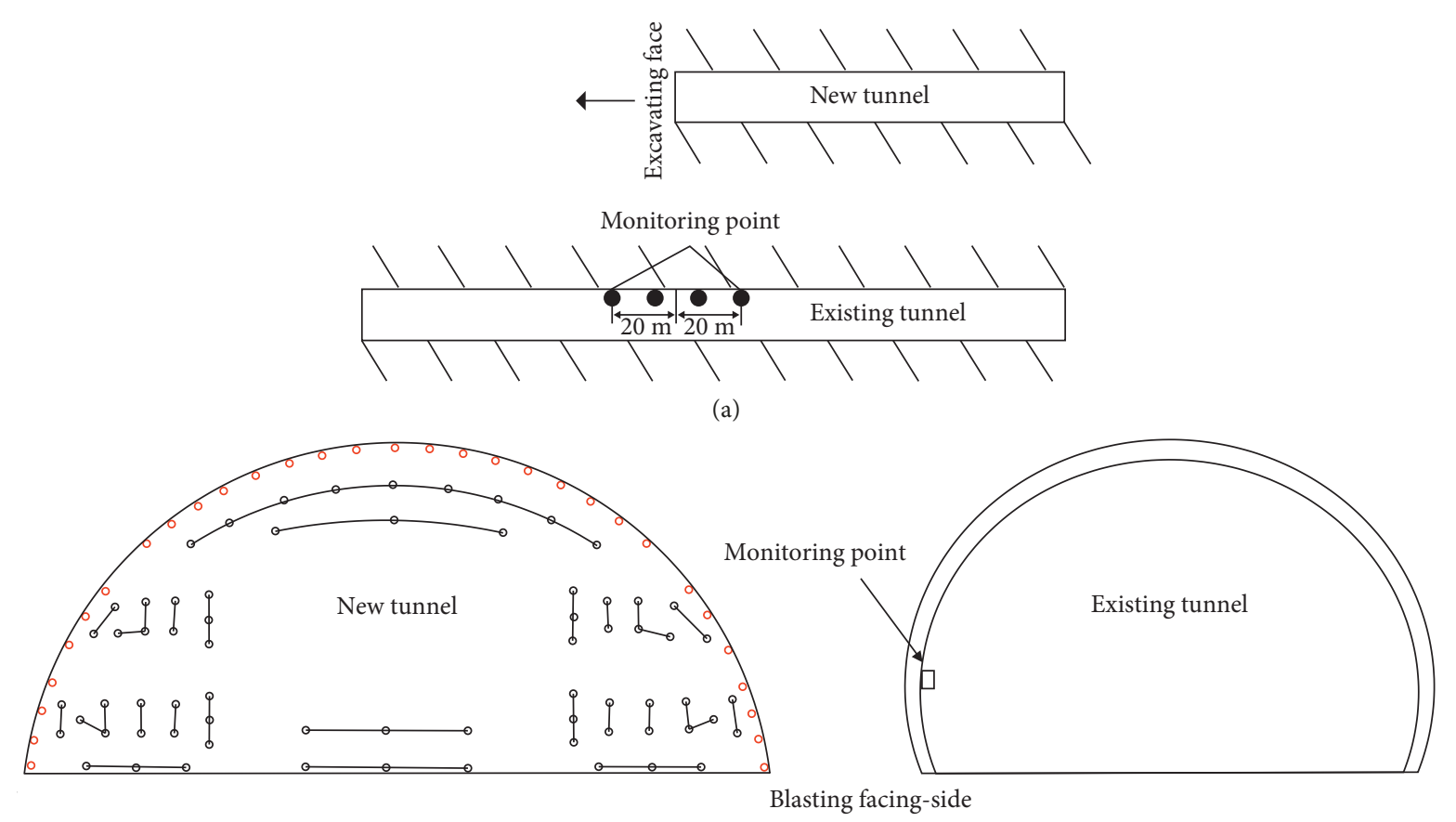

(b)

FIGURE 5: Layout scheme of PPV monitoring points for the existing tunnel. (a) Longitudinal profile. (b) Cross-sectional profile.

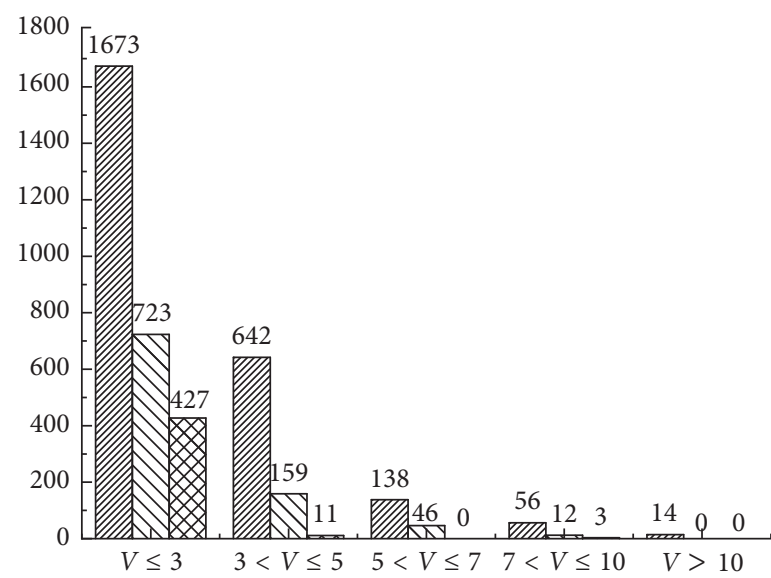

WIIITA III-grade surrounding rock

MIV IV-grade surrounding rock

V-grade surrounding rock

FIGURE 6: Cartogram for PPV distribution interval of the tunnel under different surrounding rock grades.

TABLE 7: Monitoring data of blast vibration for a typical section.

\begin{tabular}{lcccc}
\hline Simulated condition & Position & PPV of on-site monitoring $(\mathrm{cm} / \mathrm{s})$ & PPV of numerical simulation $(\mathrm{cm} / \mathrm{s})$ & Error $(\%)$ \\
\hline III-grade rock mass & YK47 +725 & 10.3 & 10.7 & 3.88 \\
IV-grade rock mass & YK47 +790 & 2.5 & 2.66 & 6.4 \\
V-grade rock mass & ZK46 + 700 & 1.9 & 2.01 & 5.79 \\
\hline
\end{tabular}

The maximum single-stage charge and the distance from the blasting source in equation (2) were each proportionally transformed, and the PPV of field monitoring is transformed into the equivalent PPV and distance from the blasting source. Assuming a unified explosive charge of $m$ and a distance from the blasting source of $n$, the equivalent PPV of $V_{\mathrm{d}}$ can be obtained by

$$
V_{\mathrm{d}}=V \times\left(\frac{m}{Q}\right)^{\alpha / 3} \times\left(\frac{R}{n}\right)^{\alpha}=K \times\left(\frac{\sqrt[3]{m}}{n}\right)^{\alpha} .
$$


TABLE 8: The slowest attenuation monitoring data of the PPV for each surrounding rock grade.

\begin{tabular}{lcccc}
\hline No. & $Q(\mathrm{~kg})$ & $R(\mathrm{~m})$ & $v(\mathrm{~cm} / \mathrm{s})$ & Surrounding rock grade \\
\hline 1 & 36.00 & 51.28 & 10.44 & \\
2 & 36.00 & 50.60 & 9.79 & \\
3 & 36.00 & 47.74 & 10.26 & III \\
4 & 31.50 & 49.28 & 8.64 & \\
5 & 41.50 & 55.69 & 7.99 & \\
6 & 18.50 & 56.88 & 4.64 & \\
7 & 24.00 & 41.06 & 8.55 & $\mathrm{IV}$ \\
8 & 41.00 & 51.01 & 7.83 & \\
9 & 30.00 & 49.09 & 6.73 & \\
10 & 5.75 & 47.17 & 2.29 & \\
11 & 5.75 & 48.63 & 2.12 & \\
12 & 12.00 & 55.68 & 2.14 & \\
13 & 5.75 & 47.82 & 1.67 & \\
14 & 18.00 & 48.02 & 3.13 & \\
15 & 18.825 & 38.78 & 4.46 & \\
16 & 6.00 & 51.44 & 1.32 & \\
\hline
\end{tabular}

According to equation (3), the monitoring data of the slowest attenuation vibration velocity under each surrounding rock grade can be obtained as shown in Table 8 . Based on the regression analysis of the slowest attenuation vibration data in Table 8, we can obtain the relationship between the maximum single-stage charge and the PPV of the existing tunnel lining as follows.

For grade III surrounding rock: $V_{\mathrm{III}}=2951.21\left(\frac{\sqrt[3]{\mathrm{Q}}}{R}\right)^{2.1}$,

For grade IV surrounding rock: $V_{\mathrm{IV}}=3801.89\left(\frac{\sqrt[3]{\mathrm{Q}}}{R}\right)^{2.29}$,

For grade V surrounding rock: $V_{\mathrm{V}}=239.88\left(\frac{\sqrt[3]{\mathrm{Q}}}{R}\right)^{2.29}$.

\section{Health Diagnosis Evaluation and Analysis of the Tunnel Lining}

By relying on dynamic monitoring only, it is difficult to fully understand and evaluate the damage caused by the blasting disturbance to the existing tunnel lining structure. Therefore, to investigate the influence of blasting vibration on the safe operation of existing tunnels when PPV is controlled within $10 \mathrm{~cm} / \mathrm{s}$, it is necessary to diagnose and evaluate the health of the existing tunnel lining structure before and after blasting. Based on the results of diagnosis and evaluation, the relationship between the PPV and the lining health is established to determine the safety threshold of PPV.

5.1. Contents and Methods of Health Diagnosis. The health diagnosis of the existing tunnel lining is mainly based on the detection of cracks in the tunnel lining. The length, width, and depth of the cracks are determined, and the cracks of the tunnel lining are divided into grades according to factors
TABLE 9: Criteria for determining crack grade.

\begin{tabular}{|c|c|c|c|}
\hline \multirow[b]{2}{*}{$\begin{array}{l}\text { Crack } \\
\text { grade }\end{array}$} & \multicolumn{3}{|c|}{ Judgment factors } \\
\hline & $\begin{array}{l}\text { Damage } \\
\text { degree }\end{array}$ & $\begin{array}{l}\text { Damage } \\
\text { development } \\
\text { trend }\end{array}$ & $\begin{array}{l}\text { Safety threats to } \\
\text { pedestrians, vehicles, } \\
\text { structures, and facilities }\end{array}$ \\
\hline B & Slight & $\begin{array}{l}\text { None or tend } \\
\text { to be stable }\end{array}$ & None or slight \\
\hline $1 \mathrm{~A}$ & Commonly & Slower & $\begin{array}{c}\text { None, it may pose a threat } \\
\text { in the future }\end{array}$ \\
\hline $2 \mathrm{~A}$ & Heavier & Fast & A certain threat and danger \\
\hline $3 \mathrm{~A}$ & Serious & Rapid & More dangerous \\
\hline
\end{tabular}

such as the development, direction, and density of the cracks. According to "Highway Tunnel Maintenance Technical Specification JTG-H12-2005” [17], the criteria for determining the grade of the lining cracks are listed in Table 9. The health evaluation of lining cracks can be divided into four grades: $\mathrm{B}, 1 \mathrm{~A}, 2 \mathrm{~A}$, and $3 \mathrm{~A}$. With the increase in crack grade, the threat to pedestrians, vehicles, structures, and facilities also increases.

5.2. Results and Analysis of Health Diagnosis. According to the comparison of the two health diagnosis results of the existing tunnel lining structure before and after the explosion, the existing tunnel lining structure includes three grades: $\mathrm{B}, 1 \mathrm{~A}$, and $\mathrm{B} \sim 1 \mathrm{~A}$. Due to the blasting disturbance of new tunnels, there are 16 cracks with a large width, 7 cracks with large length, and 13 cracks with low grades in the existing tunnel lining; all the changes of the lining cracks occurred in the $1 \mathrm{~A}$ and $\mathrm{B} \sim 1 \mathrm{~A}$ crack grade lining of the grade III and grade IV surrounding rock tunnel portions. Therefore, the safety threshold of PPV should be $10 \mathrm{~cm} / \mathrm{s}$ for intact lining and for B-grade and $\mathrm{V}$-grade linings of surrounding rock tunnel. The typical lining crack types are shown in Figure 7.

Table 10 shows the relationship between the PPV and the changes in lining health. According to Table 10, in the two health diagnoses of the existing tunnel, the grade of the lining cracks in part of the tunnel section was reduced, but none of the results of the health diagnosis before and after the change were less than $1 \mathrm{~A}$. When the crack grade is developed from $1 \mathrm{~A}$ or $\mathrm{B} \sim 1 \mathrm{~A}$ to $2 \mathrm{~A}$, pedestrians, drivers, and structural facilities are at risk. Therefore, the trend of crack development to a lower grade should be taken as an index to measure the safety threshold of PPV. For a lining crack grade that is not lower than $1 \mathrm{~A}$ and has not changed, the influence of blasting vibration on the existing tunnel lining structure can be considered to be within the allowable range.

For grade III surrounding rock, the lining crack grade does not change when the PPV is less than $5 \mathrm{~cm} / \mathrm{s}$. Moreover, the lining crack grade would be reduced when the PPV exceeds $5 \mathrm{~cm} / \mathrm{s}$. Therefore, for a lining crack grade falling between $1 \mathrm{~A}$ and $\mathrm{B}$, the threshold of PPV for a grade III surrounding rock tunnel should be $5 \mathrm{~cm} / \mathrm{s}$ to prevent the development of cracks of a lower grade.

For grade IV surrounding rocks, the lining crack grade does not change when the PPV is less than $6 \mathrm{~cm} / \mathrm{s}$. Therefore, 


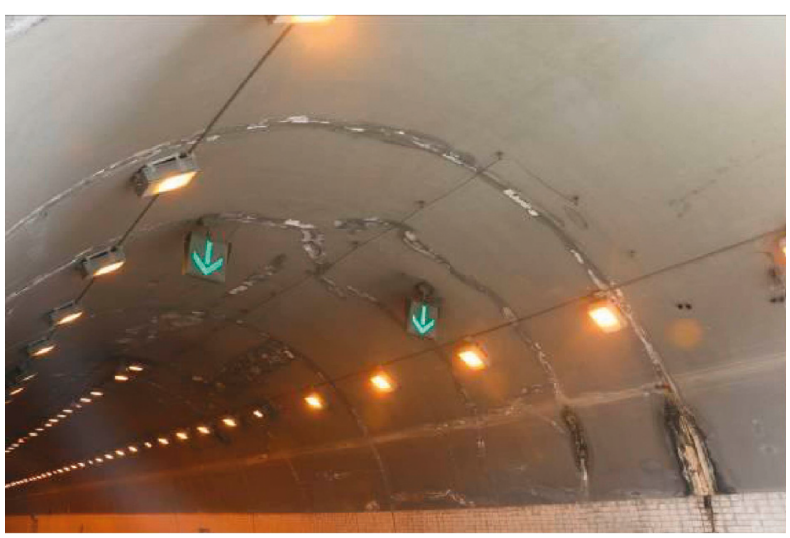

(a)

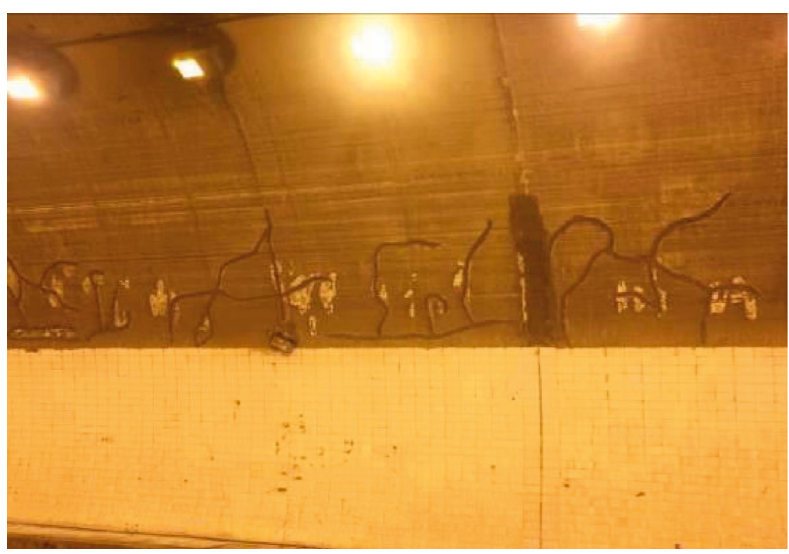

(c)

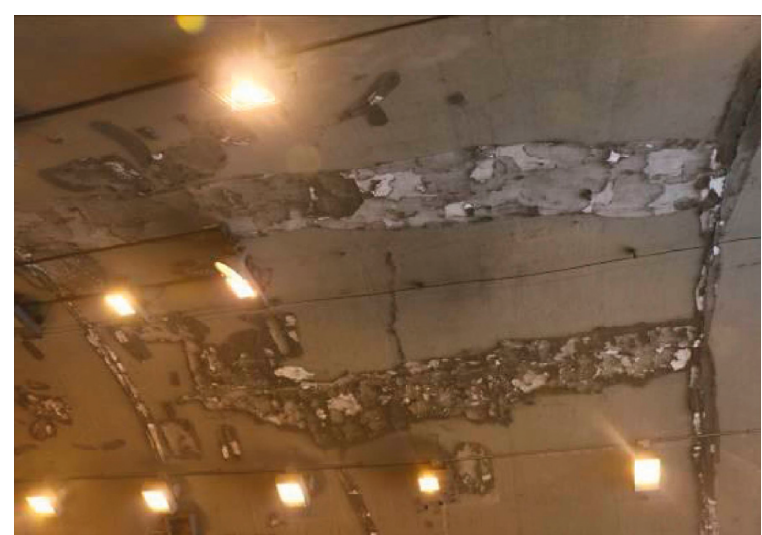

(b)

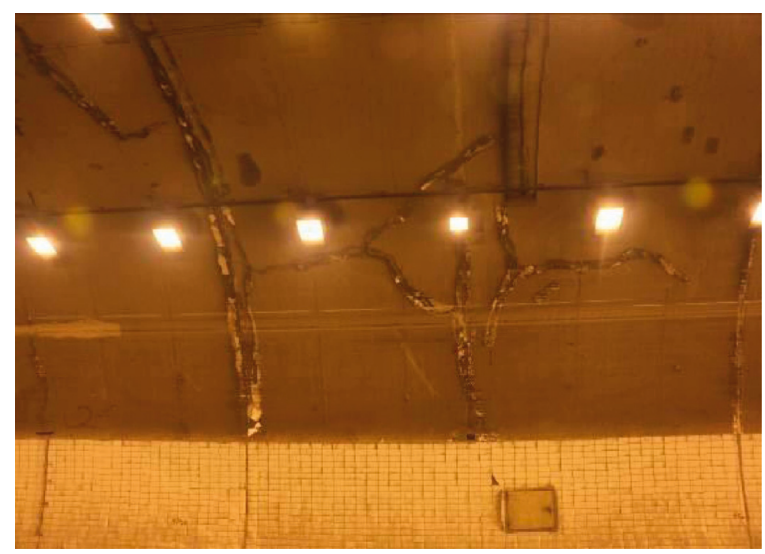

(d)

Figure 7: Typical lining cracks. (a) Circumferential cracks in the arch crown. (b) Longitudinal cracks in the arch crown. (c) Cracks in the sidewall. (d) Cracks in the spandrel.

TABLE 10: Statistics of the relationship between the PPV and the change in the healthy state of the lining.

\begin{tabular}{|c|c|c|c|c|c|c|c|c|c|}
\hline \multirow{2}{*}{$\begin{array}{l}\text { Rock } \\
\text { grade }\end{array}$} & \multirow[b]{2}{*}{$\begin{array}{c}V \leq 3 \\
(\mathrm{~cm} / \mathrm{s}) \\
\end{array}$} & \multicolumn{5}{|c|}{ Number of blasting vibration velocity distributions } & \multicolumn{2}{|c|}{ Crack grade } & \multirow[b]{2}{*}{ Change in crack } \\
\hline & & $\begin{array}{c}3<V \leq 5 \\
(\mathrm{~cm} / \mathrm{s})\end{array}$ & $\begin{array}{c}5<V \leq 6 \\
(\mathrm{~cm} / \mathrm{s})\end{array}$ & $\begin{array}{c}6<V \leq 7 \\
(\mathrm{~cm} / \mathrm{s})\end{array}$ & $\begin{array}{c}7<V \leq 8 \\
(\mathrm{~cm} / \mathrm{s})\end{array}$ & $\begin{array}{c}8<V \leq 10 \\
(\mathrm{~cm} / \mathrm{s})\end{array}$ & Before & After & \\
\hline III & 103 & 31 & 2 & 1 & 2 & - & $\mathrm{B} \sim 1 \mathrm{~A}$ & $\mathrm{~B} \sim 1 \mathrm{~A}$ & Crack width \\
\hline IV & 31 & 10 & 1 & - & - & - & $\mathrm{B} \sim 1 \mathrm{~A}$ & $\mathrm{~B} \sim 1 \mathrm{~A}$ & increased \\
\hline III & 73 & 48 & 1 & 1 & - & - & $\mathrm{B} \sim 1 \mathrm{~A}$ & $\mathrm{~B} \sim 1 \mathrm{~A}$ & Crack length \\
\hline IV & 10 & 9 & 1 & - & - & - & $\mathrm{B} \sim 1 \mathrm{~A}$ & $\mathrm{~B} \sim 1 \mathrm{~A}$ & increased \\
\hline III & 31 & 33 & 10 & - & - & - & $\mathrm{B} \sim 1 \mathrm{~A}$ & $1 \mathrm{~A}$ & $\begin{array}{l}\text { Crack grade } \\
\text { reduction }\end{array}$ \\
\hline
\end{tabular}

when the lining crack grade falls between $1 \mathrm{~A}$ and $\mathrm{B}$, the threshold of PPV for grade IV surrounding rock tunnel should be $6 \mathrm{~cm} / \mathrm{s}$ to prevent the development of cracks of a lower grade.

\section{Conclusions}

In this research, both numerical simulations and in situ vibration tests were carried out to investigate the vibrations of existing tunnels induced by the blasting excavation of new tunnels. The following points summarize the contributions of the study and the observations were made based on the results of the numerical analysis and field tests:
(1) A determination method of the safety threshold of PPV is proposed based on the dynamic response calculations of existing tunnels lining, the monitoring analysis of blasting vibration, and the statistical relationship between the safety evaluation and the PPV of the existing tunnel lining before and after blasting.

(2) The PPV facing the blasting source is larger than the PPV in the blasting backside, and the PPV facing the blasting source is approximately 1.49-1.68 times the PPV in the blasting backside. The maximum PPV of the existing tunnel lining is located at the haunch of the lining. The vertical PPV of the existing tunnel 
lining is stronger than the horizontal, and this factor should be considered. The maximum PPV of the existing tunnel is $10.7 \mathrm{~cm} / \mathrm{s}$, and it shows a significant decreasing trend with the increase in the surrounding rock grade. The maximum peak tensile stress is $0.67 \mathrm{MPa}$, and the peak tensile stress on the lining decreases with the decrease in the PPV.

(3) The PPV of the field monitoring is consistent with that of the numerical simulation, and the error is approximately 5\%. By using regression analysis on the measured vibration data, the fitting equations of maximum charge per delay for optimizing blasting excavation under different surrounding rock grades are obtained.

(4) By comparing the PPV and crack alteration on the lining before and after blasting, the recommended safety threshold of PPV is determined to be $10 \mathrm{~cm} / \mathrm{s}$ for intact lining and for B-grade and V-grade lining of the surrounding rock tunnel. Alternatively, if the lining crack grade falls between $1 \mathrm{~A}$ and $\mathrm{B}$, then the threshold PPVs of the grade III and grade IV surrounding rock tunnel should be $5 \mathrm{~cm} / \mathrm{s}$ and $6 \mathrm{~cm} / \mathrm{s}$, respectively.

\section{Data Availability}

The data used to support the findings of this study are available from the corresponding author upon request.

\section{Conflicts of Interest}

The authors declare that they have no conflicts of interest.

\section{Acknowledgments}

This study was supported by the Shaanxi Railway and Underground Traffic Engineering Key Laboratory (FSDI), Shaoxing Public Interest Research Projects (Grant No. 2017B70002 and 2017B70065), and Collaborative Innovation Center for Prevention and Control of Mountain Geological Hazards of Zhejiang Province (PCMGH-2016-Y-05).

\section{References}

[1] H.-B. Zhao, Y. Long, X.-H. Li, and L. Lu, "Experimental and numerical investigation of the effect of blast-induced vibration from adjacent tunnel on existing tunnel," KSCE Journal of Civil Engineering, vol. 20, no. 1, pp. 431-439, 2016.

[2] M. Wang, X. Pan, C. Zhang et al., "Study of blasting vibration influence on close-spaced tunnel," Rock and Soil Mechanics, vol. 25, no. 3, pp. 412-414, 2004.

[3] M. Chen, W.-B. Lu, L. Wu et al., "Safety threshold of blasting vibration velocity to high rock slope of Xiaowan hydropower station," Chinese Journal of Rock Mechanics and Engineering, vol. 26, no. 1, pp. 51-56, 2007.

[4] W.-B. Lu, H.-B. Li, M. Chen et al., "Safety criteria of blasting vibration in hydropower engineering and several key problems in their application," Chinese Journal of Rock Mechanics and Engineering, vol. 28, no. 8, pp. 1513-1520, 2009.

[5] C.-m. Lin, L.-b. Chen, L.-l. Jiang et al., "Research on blasting stability control technology of large-span highway tunnel with super-small clear spacing at highway expansion project," Chinese Journal of Rock Mechanics and Engineering, vol. 29, no. 7, pp. 1371-1378, 2010.

[6] A. Bauer and P.-n. Calder, Open Pit and Blast Seminar, Mining Engineering Department, Queens University, Kingston, Ontario, Canada, 1978.

[7] X. Xia, H. B. Li, J. C. Li, B. Liu, and C. Yu, "A case study on rock damage prediction and control method for underground tunnels subjected to adjacent excavation blasting," Tunnelling and Underground Space Technology, vol. 35, pp. 1-7, 2013.

[8] S. Sun, L. Yue, J. Wu, J. Liu, and J. Wei, "Case study on influence of step blast-excavation on support systems of existing service tunnel with small interval," Advances in Mechanical Engineering, vol. 5, Article ID 257457, 2015.

[9] Q. Liang, J. Li, D. Li, and E. Ou, "Effect of blast-induced vibration from new railway tunnel on existing adjacent railway tunnel in Xinjiang, China," Rock Mechanics and Rock Engineering, vol. 46, no. 1, pp. 19-39, 2013.

[10] J. Xu, Y. Kang, X. Wang, G. Feng, and Z. Wang, "Dynamic characteristics and safety criterion of deep rock mine opening under blast loading," International Journal of Rock Mechanics and Mining Sciences, vol. 119, pp. 156-167, 2019.

[11] L. Duan, W. Lin, J. Lai, P. Zhang, and Y. Luo, "Vibration characteristic of high-voltage tower influenced by adjacent tunnel blasting construction," Shock and Vibration, vol. 2019, Article ID 8520564, 16 pages, 2019.

[12] R. Huo, S. Li, Z. Song et al., "Analysis of vibration response law of multistory building under tunnel blasting loads," Advances in Civil Engineering, vol. 2019, Article ID 4203137, 16 pages, 2019.

[13] B. Duan, H. Xia, and X. Yang, "Impacts of bench blasting vibration on the stability of the surrounding rock masses of roadways," Tunnelling and Underground Space Technology, vol. 71, pp. 605-622, 2018.

[14] The Professional Standards Compilation Group of China, Code for Design of Road Tunnel, JTGD70-2004, China Communications Press, Beijing, China, 2004.

[15] Standardization Administration of China, Chinese National Standard GB6722-2014: Safety Regulation for Blasting, Standardization Administration of China, 2015.

[16] Livermore Software Technology Corporation, LS-DYNA Keyword User's Manual, Livermore Software Technology Corporation, Livermore, CA, USA, 2006.

[17] The Professional Standards Compilation Group of China, Highway Tunnel Maintenance Technical Specification, JTGH12-2005, China Communications Press, Beijing, China, 2005. 


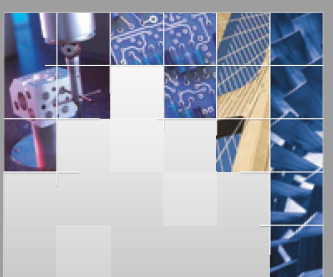

\section{Enfincering}
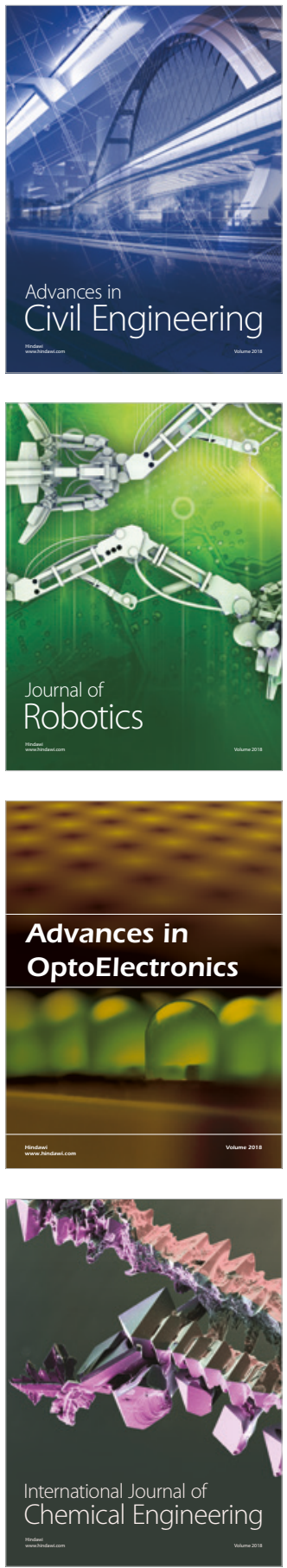

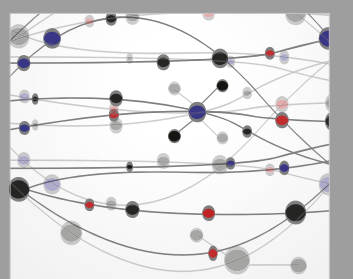

\section{Rotating \\ Machinery}

The Scientific World Journal

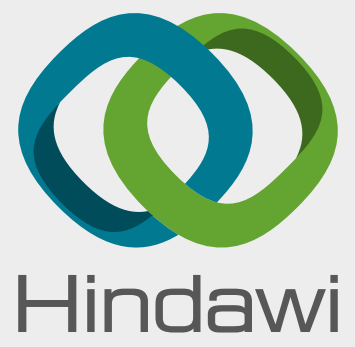

Submit your manuscripts at

www.hindawi.com
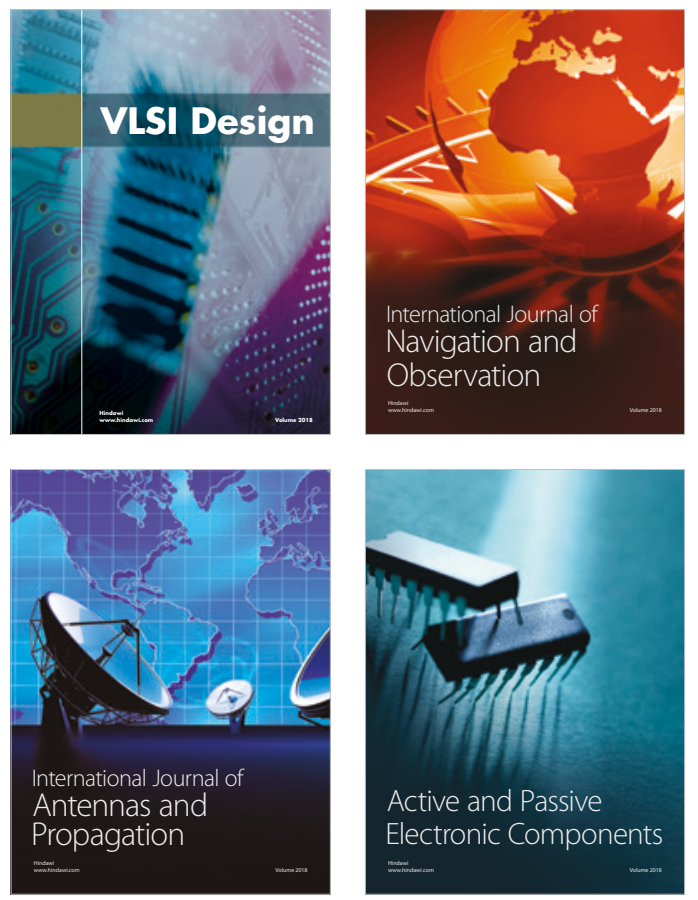
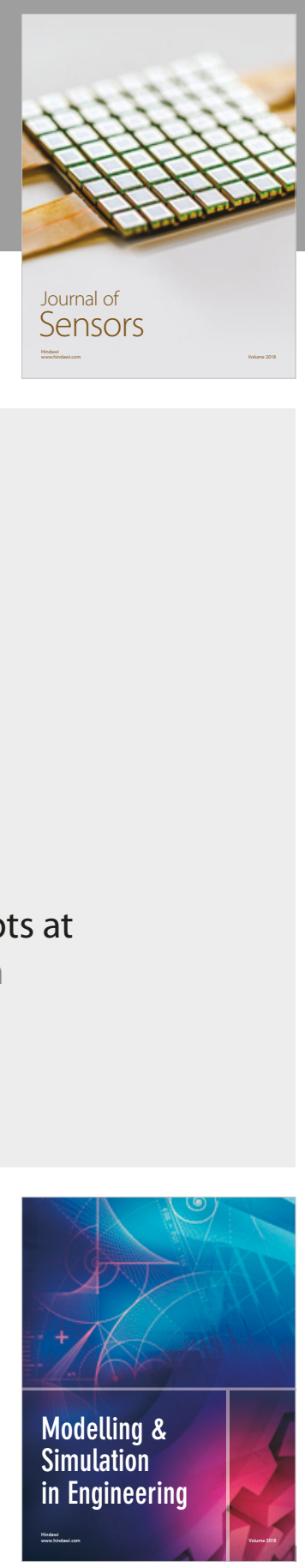

\section{Advances \\ Multimedia}
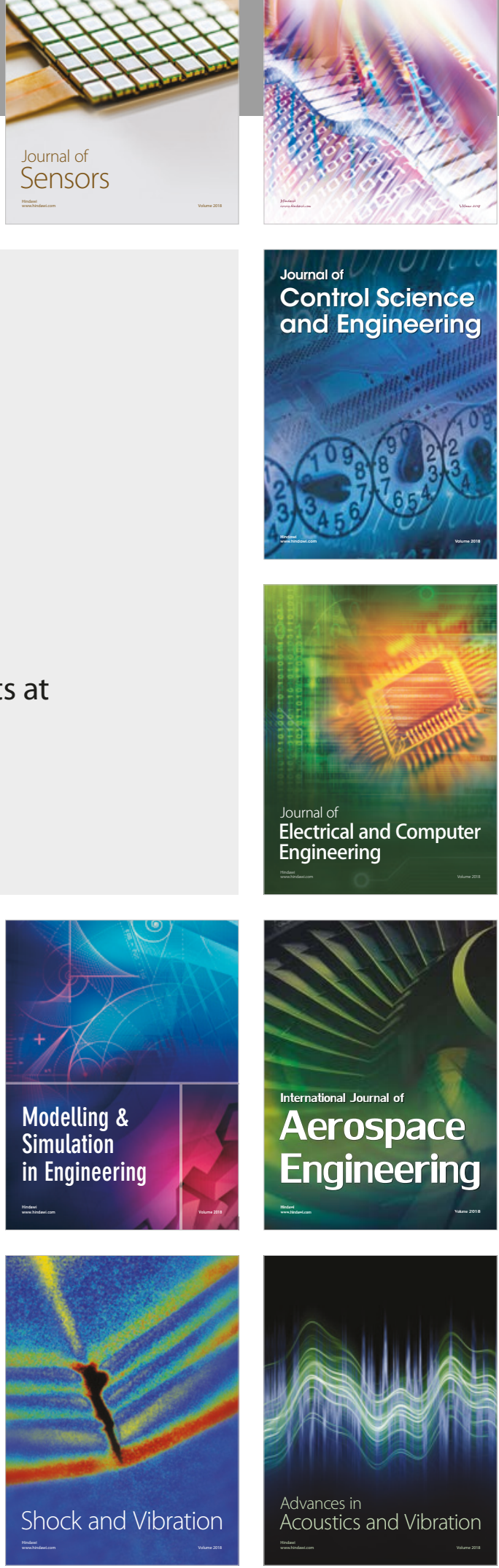